\title{
Formulation and Evaluation of Solid Dispersion Tablet of Andrographis paniculata Extract
}

\author{
Sachin Annasaheb Nitave ${ }^{1,2^{*}}$, Nilesh B. Chougule ${ }^{1,3}$, Kailasam Koumaravelou ${ }^{4}$
}

\section{Sachin Annasaheb \\ Nitave ${ }^{1,2^{*}}$, Nilesh B. \\ Chougule ${ }^{1,3}$, Kailasam \\ Koumaravelou ${ }^{4}$}

'Research Scholar, Centre for Research and Development, PRIST University, Vallam, Thanjavur, 613 403,

Tamil Nadu, INDIA.

2Principal, Dr. J. J. Magdum Trust's Anil alias Pintu Magdum Memorial

Pharmacy College Dharangutti,

416101, Shirol, Kolhapur,

Maharashtra, INDIA.

${ }^{3}$ Principal, Annasaheb Dange College of Pharmacy, Ashta, Sangli,

Maharashtra, INDIA.

${ }^{4}$ Director, PRIST University, Puducherry

Campus, 605007, Puducherry, INDIA.

\section{Correspondence}

Mr. Sachin Annasaheb Nitave

'Research Scholar, Centre for Research and Development, PRIST University, Vallam, Thanjavur, 613 403, Tamil Nadu, INDIA.

${ }^{2}$ Principal, Dr. J. J. Magdum Trust's Anil Alias Pintu Magdum Memorial Pharmacy College Dharangutti, 416101, Shirol, Kolhapur, Maharashtra, INDIA.

Phone no : 09890025364

E-mail: nitaves@yahoo.com

\section{History}

- Submission Date: 09-06-2018.

- Review completed: 19-06-2018;

- Accepted Date: 11-07-2018

DOI : 10.5530/pj.2018.5.177

Article Available online

http://www.phcogj.com/v10/i5

\section{Copyright}

(C) 2018 Phcog.Net. This is an openaccess article distributed under the terms of the Creative Commons Attribution 4.0 International license.

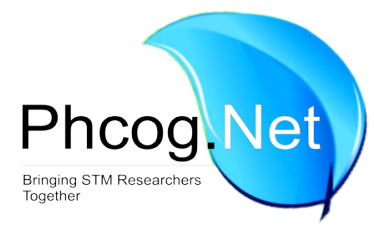

\begin{abstract}
Objective: To enhance solubility of ethanolic extract of Andrographis paniculata by solid dispersion technique and to perform formulation and evaluation of solid dispersion tablet. Materials and Methods: Solid dispersion of Andrographis paniculata extract has been prepared by solvent evaporation technique using soluplus and PEG 6000. Prepared solid dispersions have been evaluated for various micromeritic properties. The tablets of solid dispersion were prepared by direct compression technique and were evaluated for various physical tests and in-vitro dissolution study. Results: The study showed that prepared solid dispersion has good flow property and compressibility. The solubility of extract was found to be more from solid dispersion prepared by using soluplus than that of prepared by using PEG 6000 . The rate of drug release was found to be higher in acidic buffer at pH 1.2 as compared to that of in phosphate buffer at $\mathrm{pH}$ 6.8. Conclusion: The study concludes that the solid dispersion tablet of ethanolic extract of Andrographis paniculata can be effectively prepared using soluplus by solvent evaporation technique so as to increase solubility, dissolution and hence oral bioavailability of andrographolide.
\end{abstract}

Key words: Andrographis paniculata, Ethanolic extract, Solid dispersion, Soluplus, PEG 6000, Solvent evaporation technique.

\section{INTRODUCTION}

Andrographis paniculata is native to Tai- wan, Mainland China, Srilanka and India. It is also commonly found in the tropical and subtropical Asia, Southeast Asia and some other countries including Cambodia, Caribbean islands, Indonesia, Laos, Malaysia, Myanmar, Sri Lanka, Thailand and Vietnam. This plant is also found in different phytogeographical and edaphic zones of China, America, West Indies and Christmas Island. Andrographis paniculata is commonly known as King of Bitters or kalmegh. ${ }^{1}$

The plant mainly contains bitter diterpenoid lactone andrographolide which is shown in Figure 1 and other related compounds like deoxy andrographolide, 11, 12-didehydro-14-deoxy-andrographolide, neoandrographolide and andropanoside. In traditional medicine Andrographis paniculata is widely used to get rid of body heat, dispel toxins from the body, to prevent the common cold, upper respiratory tract infection and as an antidote against poisons of snakes and insects. ${ }^{2-6}$ The plant has been reported to exhibit a various modes of biological activities in-vitro as well as in-vivo viz. antibacterial, antiviral, anti-inflammatory, anti-HIV, immunostimulatory and anticancer. The plant showed potential therapeutic action in curing liver disorders in humans. The characteristic secondary metabolites encountered in this plant have considerably

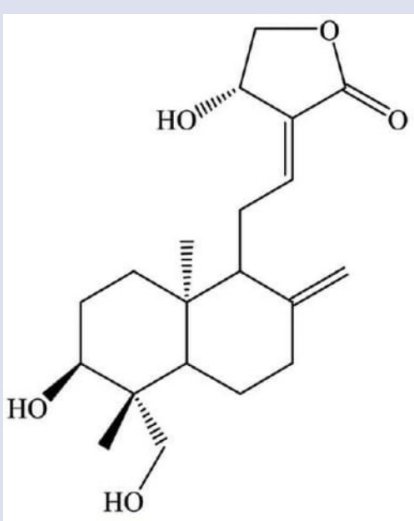

Figure 1: Chemical structure of Andrographolide-1.

enhanced its importance in the arena of medicinal plants. $^{7-12}$

Authors have already done phytochemical investigation, analgesic and antipyretic activities of ethanolic extract of Andrographis paniculata. The findings of study indicated that ethanolic extract of Andrographis paniculata have significant analgesic and antipyretic activity. ${ }^{13}$ The extracted andrographolide has poor water solubility hence need to enhance solubility so 
as to increase the absorption and oral bioavailability. Hence the objective of present study is to enhance solubility of ethanolic extract of Andrographis paniculata by solid dispersion technique and to perform formulation and evaluation of solid dispersion tablet.

\section{MATERIALS AND METHODS}

Materials

Ethanolic extract of Andrographis paniculata aerial part was prepared and used. Lactose and starch were procured from Loba Chemie Pvt. Ltd., Mumbai. Soluplus was procured from BASF, Mumbai. PEG 6000 was obtained from Merck India Ltd., Mumbai. All other chemicals used were of analytical grade.

\section{Methods}

Preparation of Solid dispersion of Andrographis paniculata extracts using solvent evaporation technique

Solid dispersions of Andrographis paniculata extract and polymer such as soluplus and PEG-6000 were prepared by solvent evaporation method. The ratio of Andrographis paniculata extract (equivalent to $50 \mathrm{mg}$ of andrographolide) to polymer was taken as 1:1, 1:2 and 1:3. Composition of each ingredient is shown in Table 1. The Andrographis paniculata extract and polymer were separately dissolved in sufficient quantity of methanol. The clear solutions of extract and polymer were mixed and then the solvent was evaporated in water bath at $50^{\circ} \mathrm{C}$ till dryness. The dried sample of dispersion was kept in desiccator until further study. To this dried dispersion required quantity of micro crystalline cellulose (MCC) and talc were added as a diluent and lubricant respectively and then pulverized using a mortar and pestle. Mixture was passed through 50-mesh sieve $(300 \mu \mathrm{m})$ and used for evaluation of micromeritic properties. ${ }^{14-15}$

\section{Evaluation of solid dispersion ${ }^{16-17}$}

Solid dispersion of Andrographis paniculata extract was evaluated for micromeritic properties such as angle of repose, bulk density, tapped density, Carr's index, hausners ratio etc.

\section{Photo microscopic image}

Photo microscopic image of solid dispersion was carried out by using motic microscope (Motic Microscope- B 1 Series) at $720 \star 576$ resolutions.

\section{Angle of Repose}

The angle of repose of solid dispersion was determined by funnel method. Accurately weighed quantity of solid dispersion was taken in a funnel. Height of the funnel was adjusted in such a way that the tip of the funnel just touches the apex of the heap of dispersion. The dispersion was allowed to flow through funnel freely onto the surface. The diameter of the powder cone was measured and angle of repose was calculated by using the following equation.

$$
\tan \theta=h / r
$$

Where $\theta=$ angle of repose, $h=$ height of the cone and $r=$ radius of the cone base

\section{Bulk density}

Both loose bulk density (LBD) and tapped bulk density (TBD) were determined. A quantity of $2 \mathrm{~g}$ of solid dispersion of each formulation which was previously lightly shaken to break any agglomerates formed and introduced into a $10 \mathrm{ml}$ measuring cylinder. After checking the initial volume was observed, the cylinder was allowed to fall under its own weight onto a hard surface from a height of $2.5 \mathrm{~cm}$ after every $2 \mathrm{sec}$. The tapping was being continued until no further change in volume was noted. LBD and TBD were calculated by using the following formulas.

LBD $=$ Weight of powder / Volume of packing

$\mathrm{TBD}=$ Weight of powder / Tapped volume of packing

\section{Compressibility Index}

The compressibility of the granules was determined by Carr's Compressibility Index by using following formula.

Carr's compressibility index $(\%)=[(\mathrm{TBD}-\mathrm{LBD}) \times 100] / \mathrm{TBD}$

\section{Hausners ratio}

A similar index like compressibility index has been defined by Hausners. Hausners ratio can be calculated by formula:

Hausners ratio $=\mathrm{TBD} / \mathrm{LBD}$

\section{Percent Yield}

The prepared solid dispersion was weighed and compared to the initial weight. The percentage yield of solid dispersion prepared by solvent evaporation method was determined by using the following formula:

$$
\text { Percent yield }=\frac{\text { Weight of prepared solid dispersion }}{\text { Weight of extract }+ \text { polymer }} \times 100
$$

\section{Determination of Saturation Solubility of Andrographis paniculata extract and Solid Dispersion ${ }^{18}$}

Saturation solubility was determined by dispersing a known excess amount of Andrographis paniculata extract and solid dispersions into $10 \mathrm{ml}$ of distilled water. The suspensions were stirred using mechanical shaker at $37 \pm 0.5^{\circ} \mathrm{C}$ for $48 \mathrm{~h}$. At the end of this samples were withdrawn and centrifuged at $10000 \mathrm{rpm}$ for $10 \mathrm{~min}$ to separate un-dissolved extract. The supernatant was taken and diluted with methanol. This solution was filtered through $0.45-\mathrm{mm}$ Whatman filter paper and solubility was quantified by using UV-spectroscopy (Jasco V-530, Japan) at $224 \mathrm{~nm}$. The results of triplicate measurements and their means were reported.

\begin{tabular}{|c|c|c|c|c|c|c|}
\hline \multirow{2}{*}{ Content } & \multicolumn{6}{|c|}{ Formulation Code } \\
\hline & $\mathrm{F} 1$ & F2 & F3 & F4 & F5 & F6 \\
\hline Andrographis paniculata extract (equivalent to $50 \mathrm{mg}$ of andrographolide) & 100 & 100 & 100 & 100 & 100 & 100 \\
\hline PEG 6000 & - & - & - & 50 & 100 & 150 \\
\hline Talc & 2 & 2 & 2 & 2 & 2 & 2 \\
\hline Total weight of Tablet (mg) & 260 & 260 & 260 & 260 & 260 & 260 \\
\hline
\end{tabular}

Table 1: Composition of solid dispersion of Andrographis paniculata extract

*All ingredients were taken in mg per tablet. 


\section{Preparation of Solid dispersion tablet}

To dried solid dispersion of each formulation required quantity of micro crystalline cellulose (MCC) and talc were added as a diluent and lubricant respectively and then pulverized using mortar and pestle. Mixture was passed through 50 -mesh sieve $(300 \mu \mathrm{m})$. Then required quantity of magnesium stearate was added as an anti-adherent and mixed well. The prepared dispersion was compressed into tablet using $8 \mathrm{~mm}$ punch on 8 station rotary tablet Press. ${ }^{19}$

\section{Evaluation of Tablet ${ }^{20-21}$}

The solid dispersion tablet of Andrographis paniculata extract was evaluated for following different parameters.

\section{Thickness and Diameter}

Thickness and diameter of tablet was determined using digital Vernier caliper (Mitutoyo Corporation India). Five tablets from each batch were used and their average values were calculated.

\section{Hardness}

For each formulation, the hardness of 6 tablets was determined using calibrated Monsanto hardness tester (Cadmach). The tablet was held along to its oblong axis in between the two jaws of the tester. At this point reading should be zero $\mathrm{kg} / \mathrm{cm}^{2}$. Then constant force was applied by rotating the knob until the tablet gets fractured. The value at this point was noted in $\mathrm{kg} / \mathrm{cm}^{2}$ which indicates hardness of tablets.

\section{Friability}

For each formulation the friability was determined by using 20 tablets and Roche friabilator (Lab Hosp.). The tablets are subjected to combined effect of shock abrasion by utilizing a plastic chamber which revolves at a speed of $25 \mathrm{rpm}$ and drops the tablets to a distance of 6 inch in each revolution. A sample of pre-weighed 20 tablets was placed in Roche friabilator which was then operated for 100 revolutions for $4 \mathrm{~min}$. then the tablets were de-dusted and reweighed. A loss of less than $1 \%$ in weight is generally acceptable. Percent friability (\% F) was calculated as follows:

$$
\% \mathrm{~F}=\frac{\text { Loss in weight }}{\text { Initial weight }} \times 100
$$

\section{Weight variation Test}

To study weight variation test 20 tablets of each formulation were weighed using an electronic balance (Citizen, CY-104) and the test was performed according to the official method.

\section{Drug content}

Five tablets were weighed individually and these tablets were crushed in a mortar. Drug equivalent to $10 \mathrm{mg}$ of powder was dissolved in a suitable quantity of methanol by using an ultrasonicator and filtered through Whatman filter paper. The drug content was determined at $224 \mathrm{~nm}$ using UV spectrophotometer (Jasco V-530, Japan) after suitable dilutions.

\section{In-vitro Drug Release Studies ${ }^{22}$}

In-vitro drug release study for the prepared solid dispersion tablets was conducted using a six-station USP type II (paddle) apparatus at $37^{\circ} \mathrm{C} \pm$ $0.5^{\circ} \mathrm{C}$ and $100 \mathrm{rpm}$ speed. The dissolution studies were carried out in two different dissolution media such as acidic buffer of $\mathrm{pH} 1.2$ and phosphate buffer of pH 6.8. Samples were withdrawn at 5, 10, 15, 30, 45, 60, 90 and $120 \mathrm{~min}$ and replaced with fresh dissolution media. After filtration through Whatman filter paper, required quantity of methanol was added and concentration of andrographolide was determined UV-spectrophotometrically at $224 \mathrm{~nm}$.

\section{Compatibility study ${ }^{23}$}

Optimized formulation prepared by using soluplus containing solid dispersion of Andrographis paniculata extract was evaluated for compatibility study between andrographolide by using IR, DSC and XRD.

\section{Infrared spectroscopy}

Fourier transform- infrared (FT-IR) spectra of Andrographis paniculata extract, soluplus and 1:1 physical mixture of extract and soluplus were obtained on FT-IR (Bruker Alpha-T, India). The spectra were scanned over the wave number range from $4000-600 \mathrm{~cm}^{-1}$.

\section{Differential Scanning Calorimetry}

Thermograms of Andrographis paniculata extract, soluplus and solid dispersion were obtained using a DSC instrument (Mettler Toledo, DSC1) equipped with an intracooler. Indium standard was used to calibrate the DSC temperature and enthalpy scale. The powder samples of granules was hermetically sealed in an aluminum pan and heated at constant rate $10^{\circ} \mathrm{C} / \mathrm{min}$ over a temperature range of $30^{\circ} \mathrm{C}$ to $250^{\circ} \mathrm{C}$. Inert atmosphere was maintained by purging nitrogen at the flow rate of $100 \mathrm{ml} / \mathrm{min}$.

\section{$X$-ray Diffractometry}

The X-ray diffraction patterns of granules were determined using a Phillips PW- 3710 X-ray diffractometer. Sample of Andrographis paniculata extract, soluplus and solid dispersion were irradiated with monochromatized $\mathrm{Cu} \mathrm{Ka}$ radiation $\left(1.542 \mathrm{~A}^{0}\right)$ and analyzed between $2^{\circ}$ and $60^{\circ}$ $(2 \theta)$. The range and chart speed were $2 X 10^{3}$ cycle per sec and $10 \mathrm{~mm} / 2 \theta$ respectively.

\section{RESULTS}

\section{Micromeritic properties of solid dispersion of Andrographis paniculata extract}

Photo microscopic image of Andrographis paniculata extract showed irregular crystals of extract. Whereas in the photo microscopic image of solid dispersion, crystals of extract was not observed on the surface of solid dispersion. This may be due to complete dispersion of extract into carriers. It was shown in Figure 2.

All formulations of solid dispersions were found to be pale yellow, free flowing and odourless powder. Results of angle of repose, bulk and tapped density, compressibility index, Hausners ratio and percent yield are summarized in Table 2.
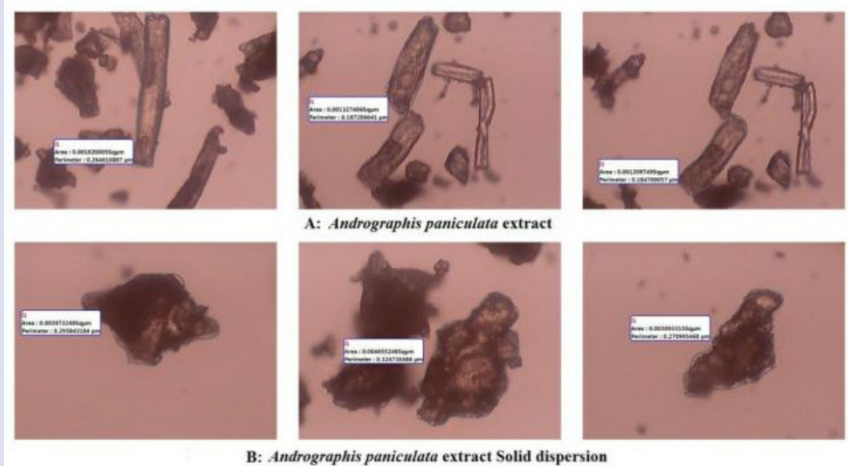

B: Andrographis paniculata extract Solid dispersion

Figure 2: Photo microscopic image of A Andrographis paniculata extract and B Solid dispersion. 
Table 2: Micromeritic properties of solid dispersion of Andrographis paniculata extract

\begin{tabular}{ccccccc}
\hline Formulation & Angle of repose* & Bulk density* $(\mathbf{g} / \mathrm{mL})$ & Tapped density* $(\mathbf{g} / \mathrm{mL})$ & Compressibility index* $(\%)$ & Hausners ratio* & $\%$ yield \\
\hline F1 & $18.34 \pm 0.05$ & $0.347 \pm 0.02$ & $0.442 \pm 0.03$ & $21.49 \pm 0.04$ & $1.27 \pm 0.04$ & 92.54 \\
F2 & $16.87 \pm 0.04$ & $0.423 \pm 0.04$ & $0.536 \pm 0.04$ & $21.08 \pm 0.03$ & $1.26 \pm 0.03$ & 94.56 \\
F3 & $14.85 \pm 0.03$ & $0.457 \pm 0.03$ & $0.532 \pm 0.04$ & $14.09 \pm 0.02$ & $1.16 \pm 0.04$ & 98.63 \\
F4 & $22.52 \pm 0.04$ & $0.687 \pm 0.04$ & $0.825 \pm 0.05$ & $16.72 \pm 0.02$ & $1.20 \pm 0.02$ & 85.47 \\
F5 & $23.65 \pm 0.03$ & $0.440 \pm 0.03$ & $0.532 \pm 0.04$ & $17.29 \pm 0.04$ & $1.20 \pm 0.04$ & 88.25 \\
F6 & $25.32 \pm 0.03$ & $0.397 \pm 0.01$ & $0.474 \pm 0.02$ & $16.24 \pm 0.04$ & $1.19 \pm 0.02$ & 90.27 \\
\hline
\end{tabular}

* All values represent mean \pm standard deviation $(n=3)$

Table 3: Saturation solubility of Andrographis paniculata extract and solid dispersion formulations in water

\begin{tabular}{cc}
\hline Batch & Solubility $(\mu \mathrm{g} / \mathrm{mL})$ \\
\hline Andrographis paniculata extract & $2.98 \pm 0.32$ \\
F1 & $9.82 \pm 0.47$ \\
F2 & $13.24 \pm 0.74$ \\
F3 & $17.20 \pm 0.82$ \\
F4 & $4.48 \pm 0.88$ \\
F5 & $6.63 \pm 0.42$ \\
F6 & $7.25 \pm 0.56$ \\
\hline
\end{tabular}

${ }^{*}$ All values represent mean \pm standard deviation $(\mathrm{n}=3)$.

Table 4: Evaluation of solid dispersion tablet

\begin{tabular}{|c|c|c|c|c|c|c|c|}
\hline $\begin{array}{l}\text { Formulation } \\
\text { code }\end{array}$ & $\begin{array}{l}\text { Thickness } \\
\text { (mm) }\end{array}$ & $\begin{array}{c}\text { Diameter } \\
(\mathrm{mm})\end{array}$ & $\begin{array}{l}\text { Hardness }(\mathrm{Kg} / \\
\left.\mathrm{cm}^{2}\right)\end{array}$ & Friability (\%) & $\begin{array}{c}\text { Weight } \\
\text { variation }\end{array}$ & $\begin{array}{l}\text { Drug content } \\
\text { (\%) }\end{array}$ & $\begin{array}{l}\text { Disintegration } \\
\text { time (min) }\end{array}$ \\
\hline $\mathrm{F} 1$ & $4.06 \pm 0.02$ & $8.13 \pm 0.04$ & $6.7 \pm 0.32$ & $0.34 \pm 0.03$ & Passes & $98.10 \pm 0.72$ & $8 \pm 1.23$ \\
\hline $\mathrm{F} 2$ & $4.08 \pm 0.04$ & $8.13 \pm 0.02$ & $6.7 \pm 0.42$ & $0.42 \pm 0.02$ & Passes & $98.77 \pm 0.30$ & $11 \pm 1.52$ \\
\hline F3 & $4.06 \pm 0.03$ & $8.13 \pm 0.02$ & $6.8 \pm 0.54$ & $0.46 \pm 0.01$ & Passes & $99.88 \pm 0.25$ & $13 \pm 0.87$ \\
\hline $\mathrm{F} 4$ & $4.05 \pm 0.03$ & $8.13 \pm 0.03$ & $6.4 \pm 0.22$ & $0.82 \pm 0.03$ & Passes & $95.25 \pm 1.05$ & $10 \pm 1.41$ \\
\hline F5 & $4.06 \pm 0.03$ & $8.13 \pm 0.02$ & $7.8 \pm 0.36$ & $0.38 \pm 0.01$ & Passes & $97.82 \pm 0.31$ & $12 \pm 0.98$ \\
\hline F6 & $4.08 \pm 0.02$ & $8.13 \pm 0.04$ & $8.2 \pm 0.28$ & $0.31 \pm 0.02$ & Passes & $98.20 \pm 1.59$ & $14 \pm 0.46$ \\
\hline
\end{tabular}

${ }^{*}$ All values represent mean \pm standard deviation $(\mathrm{n}=3)$.

\section{Saturation Solubility of Andrographis paniculata extract and Solid Dispersion}

Result showed that, solubility of Andrographis paniculata extract in distilled water was found to be $2.98 \pm 0.32 \mu \mathrm{g} / \mathrm{ml}$. Solubility of extract from solid dispersion prepared by using soluplus shows maximum solubility than that of extract. Solubility of extract was found to be more from solid dispersion which was prepared by using soluplus than that of prepared using PEG 6000. It was shown in Table 3 and Figure 3.

\section{Preparation and evaluation of solid dispersion tablet}

Tablets of all formulations (F1 to F6) were prepared by direct compression technique. The prepared tablets were evaluated for different parameters such as thickness, hardness, weight variation, drug content, friability and disintegration time. All results are summarized in Table 4.



Figure 3: Saturation solubility of Andrographispaniculata extract and solid dispersion formulations in water. 
Table 5: In-vitro \% drug release in acidic buffer at pH $\mathbf{1 . 2}$

\begin{tabular}{|c|c|c|c|c|c|c|c|}
\hline \multirow{2}{*}{ Time (min) } & \multicolumn{7}{|c|}{$\%$ drug release } \\
\hline & ANDG & F1 & F2 & F3 & F4 & F5 & F6 \\
\hline 0 & 0 & 0 & 0 & 0 & 0 & 0 & 0 \\
\hline 5 & $10.85 \pm 2.25$ & $48.78 \pm 2.55$ & $55.68 \pm 3.2$ & $60.28 \pm 5.33$ & $38.36 \pm 4.25$ & $42.36 \pm 6.14$ & $47.28 \pm 2.1$ \\
\hline 10 & $12.23 \pm 3.63$ & $56.32 \pm 4.65$ & $60.44 \pm 5.45$ & $65.35 \pm 3.84$ & $41.56 \pm 3.56$ & $44.89 \pm 2.56$ & $49.21 \pm 4.22$ \\
\hline 15 & $14.52 \pm 2.58$ & $60.39 \pm 5.41$ & $63.85 \pm 4.69$ & $68.89 \pm 2.56$ & $44.85 \pm 6.35$ & $48.62 \pm 5.23$ & $52.87 \pm 4.65$ \\
\hline 30 & $16.89 \pm 3.65$ & $63.41 \pm 3.25$ & $66.87 \pm 3.45$ & $75.41 \pm 3.44$ & $47.39 \pm 5.68$ & $52.74 \pm 2.33$ & $56.79 \pm 3.56$ \\
\hline 45 & $22.56 \pm 2.98$ & $65.74 \pm 2.65$ & $69.21 \pm 5.66$ & $79.86 \pm 6.54$ & $51.86 \pm 2.54$ & $55.96 \pm 3.51$ & $61.85 \pm 5.21$ \\
\hline 60 & $24.92 \pm 3.56$ & $68.22 \pm 2.33$ & $72.87 \pm 3.84$ & $83.69 \pm 4.22$ & $54.63 \pm 3.66$ & $58.98 \pm 3.56$ & $64.46 \pm 3.21$ \\
\hline 90 & $26.32 \pm 4.26$ & $72.86 \pm 4.21$ & $75.92 \pm 5.89$ & $85.63 \pm 5.89$ & $57.11 \pm 3.48$ & $61.35 \pm 3.85$ & $67.81 \pm 5.36$ \\
\hline 120 & $28.68 \pm 3.89$ & $75.24 \pm 2.63$ & $78.96 \pm 3.66$ & $87.69 \pm 4.12$ & $60.29 \pm 5.22$ & $64.24 \pm 6.23$ & $70.23 \pm 4.21$ \\
\hline
\end{tabular}

*All values represent mean \pm standard deviation $(n=3)$.

Table 6: In-vitro \% drug release in phosphate buffer at $\mathrm{pH} 6.8$.

\begin{tabular}{cccccccc}
\hline \multirow{2}{*}{ Time $(\min )$} & \multicolumn{7}{c}{ \% drug release } \\
\cline { 2 - 7 } & ANDG & F1 & F2 & F3 & F4 & F5 & 0 \\
\hline 0 & 0 & 0 & 0 & 0 & 0 & $29.78 \pm 5.78$ & $39.79 \pm 3.57$ \\
5 & $6.28 \pm 3.21$ & $32.82 \pm 3.47$ & $38.74 \pm 4.22$ & $44.39 \pm 4.84$ & $26.38 \pm 3.89$ & $42.88 \pm 5.79$ \\
10 & $8.41 \pm 2.86$ & $35.29 \pm 5.86$ & $41.85 \pm 3.59$ & $48.78 \pm 4.36$ & $30.17 \pm 3.41$ & $34.27 \pm 4.96$ & $38.96 \pm 5.32$ \\
15 & $11.26 \pm 4.84$ & $40.75 \pm 4.18$ & $45.29 \pm 4.85$ & $54.81 \pm 5.25$ & $33.89 \pm 2.36$ & $50.98 \pm 6.32$ \\
30 & $13.74 \pm 5.96$ & $45.32 \pm 3.87$ & $49.67 \pm 3.97$ & $59.32 \pm 4.34$ & $38.92 \pm 5.23$ & $41.89 \pm 3.69$ & $54.86 \pm 5.33$ \\
45 & $14.98 \pm 4.71$ & $49.87 \pm 5.32$ & $55.47 \pm 5.12$ & $63.71 \pm 3.87$ & $41.79 \pm 4.97$ & $46.84 \pm 2.84$ & $58.71 \pm 6.24$ \\
60 & $16.47 \pm 6.01$ & $54.98 \pm 6.02$ & $59.63 \pm 3.95$ & $68.38 \pm 3.63$ & $46.78 \pm 3.65$ & $51.39 \pm 3.86$ & $61.55 \pm 4.33$ \\
90 & $18.29 \pm 5.72$ & $60.28 \pm 4.11$ & $65.87 \pm 4.56$ & $73.92 \pm 4.26$ & $51.02 \pm 4.89$ & $55.74 \pm 5.74$ & $65.48 \pm 5.74$ \\
120 & $20.59 \pm 4.98$ & $64.78 \pm 3.86$ & $70.52 \pm 5.01$ & $78.23 \pm 4.11$ & $54.21 \pm 5.71$ & $58.79 \pm 5.86$ & $69.41 \pm 5.29$ \\
\hline
\end{tabular}

*All values represent mean \pm standard deviation $(n=3)$.

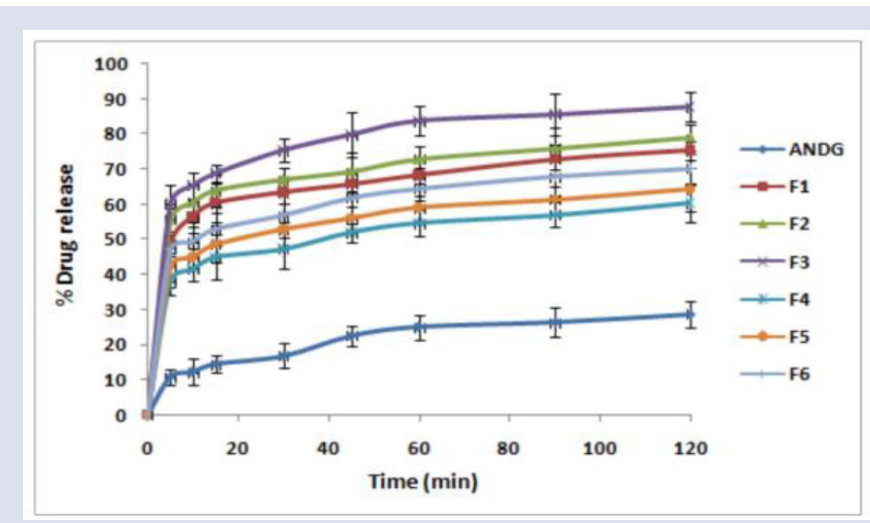

Figure 4: In-vitro \% drug release in acidic buffer at $\mathrm{pH} 1.2$.

\section{In-vitro Drug Release Studies}

The results showed that, rate of drug release are higher in acidic buffer at $\mathrm{pH}$ 1.2, that is shown in Table 5 and Figure 4, as compared to that of in phosphate buffer at pH 6.8, shown in Table 6 and Figure 5.

\section{Compatibility study}

Fourier transform-infrared (FT-IR) Spectroscopy

FTIR study was done to assess whether any possible interaction between Andrographis paniculata extract and soluplus. Infrared spectrums of

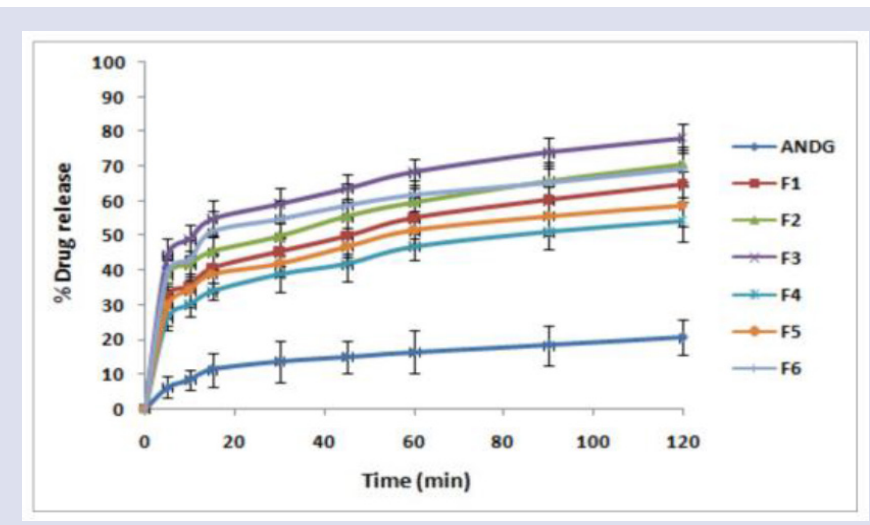

Figure 5: In-vitro \% drug release in phosphate buffer at pH 6.8.

extract, soluplus and 1:1 physical mixture of extract and soluplus are shown in Figure 6.

Results of compatibility study using FTIR showed that the fundamental peak of Andrographis paniculata extract at $902.423 \mathrm{~cm}^{-1}, 1031.077 \mathrm{~cm}^{-1}$, $1649.142 \mathrm{~cm}^{-1}, 2845.245 \mathrm{~cm}^{-1}$ and $3282.842 \mathrm{~cm}^{-1}$ attributable to various functional groups like primary and secondary amines, aliphatic amine, alkenes, alkanes, alcohols and phenols respectively. 


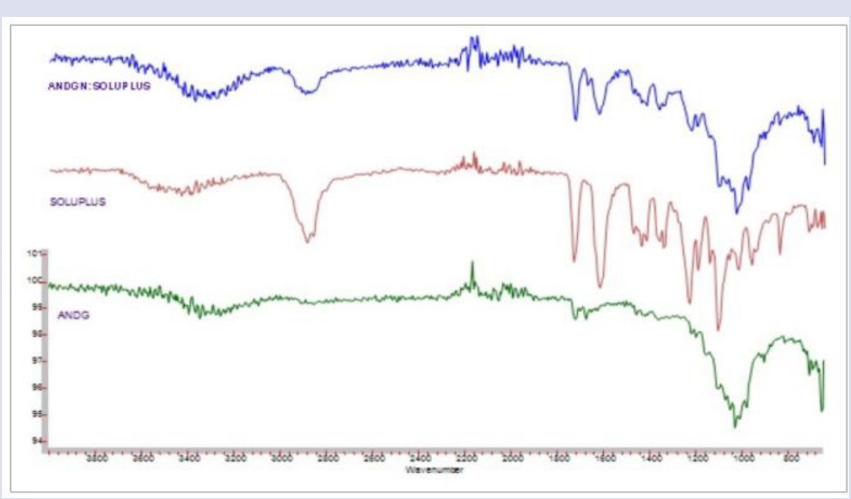

Figure 6: FT-IR Spectrum of Andrographis paniculata extract, Soluplus and 1:1 Physical mixture of extract and Soluplus.

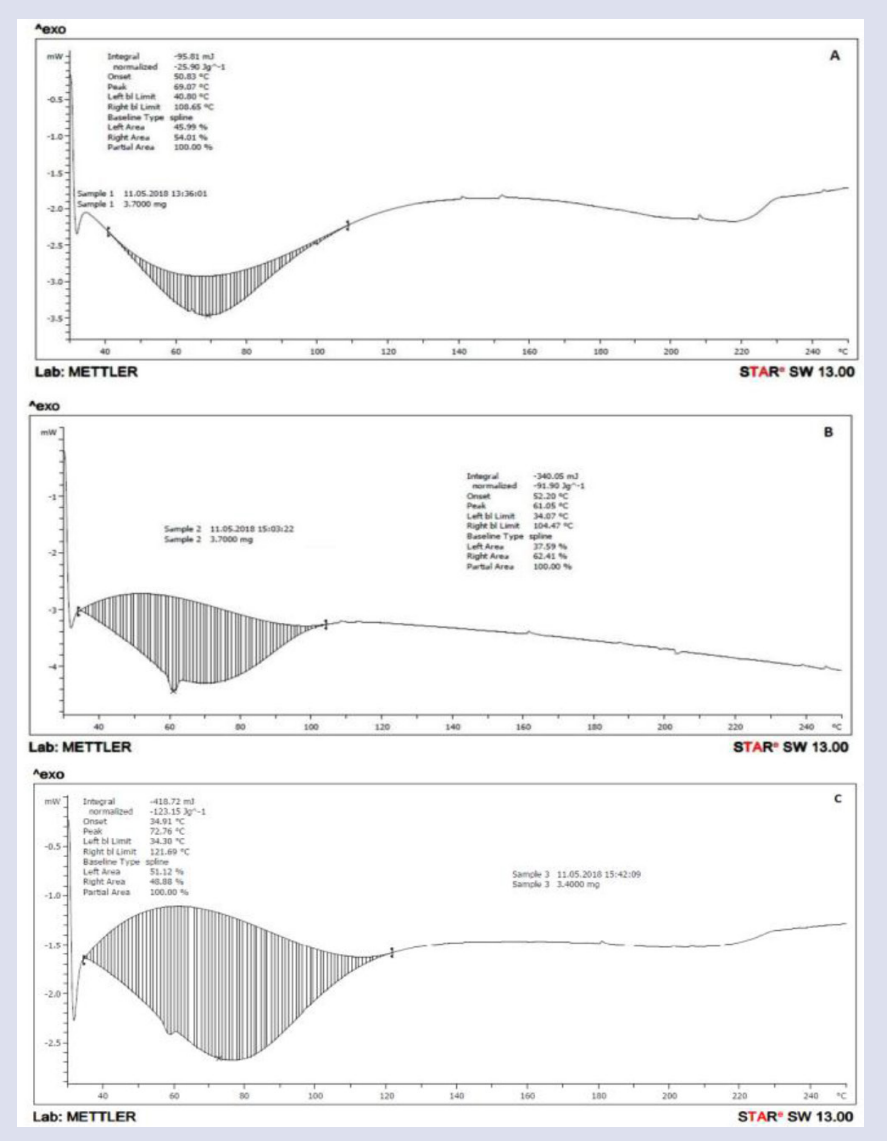

Figure 7: DSC thermogram of A Androgra phispaniculata extract, B Soluplus and C Solid dispersion.

\section{Differential Scanning Calorimetry (DSC)}

Results of DSC thermograms of Andrographis paniculata extract, soluplus and solid dispersion, showed peak at $69.07^{\circ} \mathrm{C}, 61.05^{\circ} \mathrm{C}$ and $72.76^{\circ} \mathrm{C}$ which is shown in Figure 7. Peak of Andrographis paniculata extract is slightly shifted from $69.07^{\circ} \mathrm{C}$ to $72.76^{\circ} \mathrm{C}$ in DSC thermogram of solid dispersion. It may be due to solubilization of extract in soluplus.

\section{$X$-ray Diffractometry (XRD)}

The height of the characteristic peak intensity of Andrographis paniculata extract is remarkably reduced in case of diffractogram of solid dispersion.

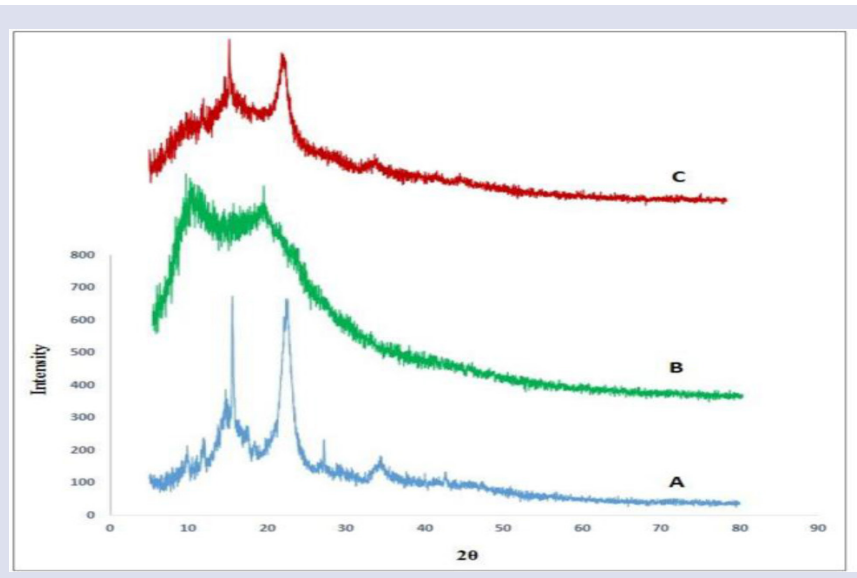

Figure 8: XRD of A Andrographis paniculata extract, B Soluplus and C Solid dispersion.

It is shown in Figure 8. This indicates that Andrographis paniculata extract may have converted to a metastable amorphous form or may have dissolved in the matrix system.

\section{DISCUSSION}

Angle of repose of all solid dispersion formulations was found to be in between $14.85 \pm 0.03$ to $25.32 \pm 0.03$. Angle of repose of solid dispersion prepared by using soluplus as a carrier (F1, F2 and F3) was found to be less than 20. Hence showed excellent flow property than that of solid dispersion prepared by using PEG 6000 as a carrier (F4, F5 and F6) which showed angle of repose more than 20. Bulk density and tapped density of all solid dispersion formulations was found to be in the range of $0.347 \pm 0.02 \mathrm{~g} / \mathrm{mL}$ to $0.687 \pm 0.04 \mathrm{~g} / \mathrm{mL}$ and $0.442 \pm 0.03 \mathrm{~g} / \mathrm{mL}$ to $0.825 \pm 0.05 \mathrm{~g} / \mathrm{mL}$ respectively.

Compressibility index and Hausners ratio of all formulations were found to be in the range of $14.09 \pm 0.02 \%$ to $21.49 \pm 0.04 \%$ and $1.19 \pm 0.02$ to $1.27 \pm 0.04$ respectively. Compressibility index of solid dispersion prepared using soluplus and PEG 6000 was found to be approximate 21 and less. Hence showed fair to passable flowability. Among all formulations, compressibility index of solid dispersion of formulation F3 was found to be less than 15 , hence it has excellent flowability. Hausners ratio of formulation F3 was found to be less than 1.25 which indicates that it has good flow property. Percent yield of all formulations of solid dispersion by solvent evaporation technique was found to be in the range of 85.47 to 98.63 . Formulation F3 showed more percent yield that is $98.63 \%$ than the other formulations.

The saturation solubility of Andrographis paniculata extract and solid dispersion study showed that there is 5.77 fold increase in solubility of Andrographis paniculata extract when solid dispersion is prepared with 1:3 proportion of soluplus. Results also showed that as concentration of soluplus and PEG 6000 increases, solubility also increases.

Examination of tablets from each batch showed flat circular shape with no cracks having pale yellow color. The thickness of tablets ranged from $4.05 \pm 0.03$ to $4.08 \pm 0.04 \mathrm{~mm}$. All formulations showed uniform thickness. In weight variation test, the pharmacopoeia limit for percent of deviation for tablets of more than $250 \mathrm{mg}$ is $\pm 5 \%$. The average percent deviation of all tablets was found to be within the limit and hence all formulations passed the weight variation test. The drug content was found to be uniform among all formulations and ranged from $95.25 \pm 1.05$ to $99.88 \pm 0.25 \%$. The hardness of tablets of all formulations were in the range of $6.4 \pm 0.22$ to $8.2 \pm 0.28 \mathrm{Kg} / \mathrm{cm}^{2}$. As the concentration of carrier's 
increases, hardness of tablet was found to be increases. Tablets of solid dispersion prepared by using PEG 6000 showed maximum hardness which was also reflected in increase in disintegration time. Disintegration time of all formulations was found to be less than $15 \mathrm{~min}$. The friability of tablets of all formulations were in the range of $0.31 \pm 0.02$ to $0.82 \pm 0.03 \%$ i.e. less than $1 \%$.

Drug released from solid dispersion tablet was found to be significantly higher as compared to plain Andrographis paniculata extract. It could be suggested that in the solid dispersion, molecular dispersion of drug in polymeric carriers may have led to particle size reduction and surface area enhancement, which results into improved dissolution rates. Furthermore no energy is required to break up the crystal lattice of a drug during dissolution process and improvement of drug solubility and wettability due to surrounding hydrophilic carriers. Thus this greater availability of dissolved extract from the solid dispersion tablet formulations may lead to higher absorption and higher oral bioavailability. Results also reveals that the solid dispersion prepared using soluplus gives higher dissolution rate as compared to that of solid dispersion prepared by using PEG 6000 as a carrier.

The compatibility study using FTIR showed that the fundamental peak of Andrographis paniculata extract are retained with slight shifting, which reveals the Andrographis paniculata extract is stable and can retain its functional ability with soluplus.

The DSC thermograms of Andrographis paniculata extract, soluplus and solid dispersion, conclude that there is no or minor incompatibility between Andrographis paniculata extract and soluplus.

Characteristic peak of Andrographis paniculata extract in was found in the diffractogram (XRD) of solid dispersion, it means that there is no incompatibility between soluplus and ethanolic extract of Andrographis paniculata.

\section{CONCLUSION}

The solubility of extract was found to be more from solid dispersion prepared by using soluplus than that of prepared by using PEG 6000 . From various batches of solid dispersion tablet of Andrographis paniculata extract, formulation F3 was selected as optimized formulation by considering drug content, aqueous solubility, percent yield and percent drug release. Rate of drug release was found to be higher in acidic buffer at $\mathrm{pH} 1.2$ as compared to that of in phosphate buffer at $\mathrm{pH}$ 6.8. Compatibility study using IR, DSC and XRD showed that, ethanolic extract is compatible with soluplus and can be used for preparation of stable formulation. Hence study concluded that, solid dispersion of Andrographis paniculata extract using soluplus can be prepared by solvent evaporation technique to enhance aqueous solubility, dissolution and hence oral bioavailability of andrographolide.

\section{CONFLICT OF INTEREST}

The authors declare no conflict of interest.

\section{ABBREVIATIONS}

PEG 6000: Polyethylene glycol 6000; A. paniculata: Andrographis paniculata; MCC: Micro crystalline cellulose; LBD: Loose bulk density; TBD: Tapped bulk density; \% F: Percent friability; IR: Infrared spectroscopy; DSC: Differential scanning calorimetry; XRD: X-ray diffractometry; FT-IR: Fourier transform infrared spectroscopy; \%: Percentage.

\section{REFERENCES}

1. Anil K, Jyotsna D, Anup S, Rishikant T. A Review on King of Bitter (Kalmegh). International Journal of research in pharmacy and chemistry. 2012;2(1):116-24.

2. Mishra SK, Sangwan NS, Sangwan RS. Andrographis paniculata (Kalmegh): A review. Pharmacognosy Review. 2007;1(2):283-98.

3. Joselin J, Jeeva S. Andrographis paniculata: A Review of its Traditional Uses, Phytochemistry and Pharmacology. Medicinal and Aromatic Plants. 2014;3(4);1-15.

4. Samy RP, Thwin MM, Gopalakrishnakone P, Ignacimuthu S. Ethnobotanical survey of folk plants for the treatment of snakebites in Southern part of Tamilnadu. Indian Journal of Ethnopharmacology. 2008;115(2):302-12.

5. Gabrielian ES, Shukarian AK, Goukasova GI, Chandanian GL, Panossian AG, Wikman G, et al. Double-blind, placebo-controlled study of Andrographis paniculata fixed combination Kan Jang in the treatment of acute upper respiratory tract infections including sinusitis. Phytomedicine. 2002;9(2):589-97.

6. Singha PK, Roy S, Dey S. Antimicrobial activity of Andrographis paniculata. Fitoterapia. 2003;74(7-8):692-4.

7. Chao WW, Kuo YH, Lin BF. Anti-inflammatory activity of new compounds from Andrographis paniculata by NF-kappaB transactivation inhibition. Journal of Agricultural and Food Chemistry. 2010;58(4):2505-12.

8. Iruretagoyena MI, Tobar JA, Gonzalez PA, Sepulveda SE, Figueroa CA. Andrographolide interferes with $T$ cell activation and reduces experimental autoimmune encephalomyelitis in the mouse. The Journal of pharmacology and experimental therapeutics. 2005;312(1):366-72.

9. Calabrese C, Berman SH, Babish JG, MaX, Shinto L. A phase I trial of andrographolide in HIV positive patients and normal volunteers. Phytother Res. 2000;14(5):333-8.

10. LiW, Xu X, Zhang H, Ma C, Fong H. Secondary metabolites from Andrographis paniculata. Chem Pharm Bull. 2007;55(3):455-8.

11. Geethangili M, Rao YK, Fang SH, Tzeng YM, Cytotoxic constituents from Andrographis paniculata induce cell cycle arrest in jurkat cells. Phytother Res. 2008;22(10):1336-41.

12. Niranjan A, Tewari SK, Lehri A. Biological activities of Kalmegh (Andrographis paniculata Nees) and its active principles-A review. Indian Journal of Natural Products Resources. 2010;1(2):125-35.

13. Nitave SA, Chougule NB, Koumaravelou K. Phytochemical investigation, analgesic and antipyretic activities of ethanolic extract of kariyat. International Journal of Pharmaceutical Sciences and Research. 2018;9(3):1000-9.

14. Sharma A, Jain CP. Preparation and characterization of solid dispersions of carvedilol with PVP K30. Research in Pharmaceuitcal Science. 2010;5(1):49-56.

15. Weerapol Y, Tubtimsri S, Jansakul C, Sriamornsak P. Improved dissolution of Kaempferia parviflora extract for oral administration by preparing solid dispersion via solvent evaporation. Asian Journal of Pharmaceutical Sciences. 2017;12(2):124-33.

16. Aulton ME. Pharmaceutics: The Science of Dosage Form Design, Churchill Livingstone: Edinburgh, Scotland, $2^{\text {nd }}$ ed. 1988;133-4

17. More HN, Hajare AA. Practical physical pharmacy, Nashik, India: Career Prakashan, $2^{\text {nd }}$ ed. 2010;129-31.

18. Changdeo JS, Musale V, Kuchekar BS, Chabukswar AR. Physicochemical char acterization and solubility enhancement studies of allopurinol solid dispersions. Brazilian Journal of Pharmaceutical Sciences. 2011;47(3):513-23.

19. Mamatha T, Naseha, Anitha N, Qureshi HK. Development of nevirapine tablets by direct compression method using solid dispersion technique. Journal of Pharmaceutical Research. 2017;16(1):72-9.

20. Banker GS, Anderson N, Lachman L, Lieberman HA, Kanig JL. The Theory and Practice of Industrial Pharmacy. Varghese publishing house: Mumbai, $3^{\text {rd }}$ ed. 1990;296-302.

21. Indian Pharmacopoeia Government of India, Ministry of Health and Family Welfare. The Controller of Publications. New Delhi, II. 1996;734-6.

22. Zhang D, Lin J, Zhang F. Preparation and Evaluation of Andrographolide Solid Dispersion Vectored by Silicon Dioxide. Pharmacogn Mag. 2016;12(Suppl 2):S245-52.

23. Chatwal GR, Anand SK. Instrumental methods of chemical analysis. Himalaya Publishing House, $5^{\text {th }}$ ed, 2002;2.318-2.331, 2.747-2.748. 
GRAPHICAL ABSTRACT

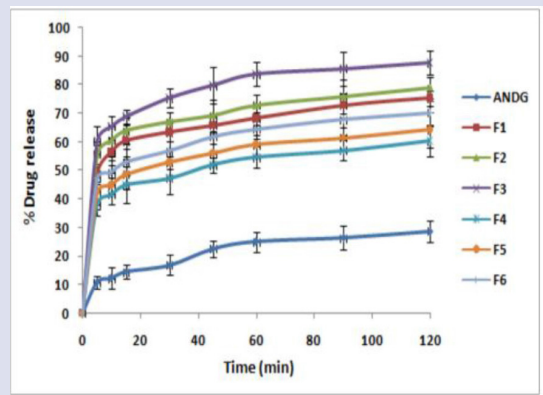

\section{SUMMARY}

- The solid dispersion tablet of ethanolic extract of Andrographis paniculata can be effectively prepared using soluplus by solvent evaporation technique so as to increase solubility, dissolution and hence oral bioavailability of andrographolide.

\section{ABOUT AUTHORS}

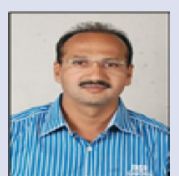

Sachin Annasaheb Nitave: (M. Pharm, Pursuing PhD), Principal, Dr. J. J. Magdum Trust's Anil alias Pintu Magdum Memorial Pharmacy College Dharangutti, 416101, Shirol, Kolhapur, Maharashtra, India.

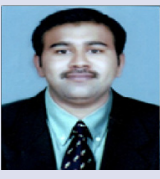

Nilesh Balasaheb Chougule: (M. Pharm, Pursuing PhD), Principal, Annasaheb Dange College of D. Pharmacy, Ashta, Sangli, Maharashtra, India.

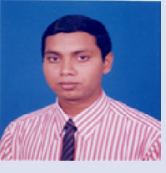

Dr. Kailasam Koumaravelou: Director, PRIST University, Puducherry Campus, 605007, Puducherry, Tamil Nadu, India. 